\title{
Factors Related to Posttraumatic Stress Disorder in Adolescence
}

TRAUMA, VIOLENCE, \& ABUSE $000(00) \mathrm{I}-\mathrm{I} 4$

(C) The Author(s) 2012

Reprints and permission:

sagepub.com/journalsPermissions.nav DOI: $10.1177 / 1524838012447698$

http://tva.sagepub.com

(S)SAGE

\author{
Kate B. Nooner ${ }^{1,2}$, L. Oriana Linares ${ }^{3}$, Jessica Batinjane', \\ Rachel A. Kramer', Raul Silva ${ }^{4}$, and Marylene Cloitre ${ }^{5}$
}

\begin{abstract}
Studies of posttraumatic stress disorder (PTSD) in adolescence published from 2000 to $20 \mathrm{II}$ indicate that adolescents are at greater risk of experiencing trauma than either adults or children, and that the prevalence of PTSD among adolescents is 3-57\%. Age, gender, type of trauma, and repeated trauma are discussed as factors related to the increased rates of adolescent PTSD. PTSD in adolescence is also associated with suicide, substance abuse, poor social support, academic problems, and poor physical health. PTSD may disrupt biological maturational processes and contribute to the long-term emotion and behavior regulation problems that are often evident in adolescents with the disorder. Recommendations are presented for practice and research regarding the promotion of targeted prevention and intervention services to maximize adolescents' strengths and minimize vulnerabilities. Public policy implications are discussed.
\end{abstract}

\section{Keywords}

adolescent, trauma, posttraumatic stress, abuse, development, risk factors, suicidality, substance use

\section{Key Points of the Research Review}

Trauma in Adolescence

- Four of five adolescents meet DSM criteria for exposure to a serious traumatic event. Of these, 3-57\% meet diagnostic criteria for Posttraumatic Stress Disorder (PTSD).

- Child maltreatment is a common type of trauma for those under 18. There were over 2 million reported cases in the United States in 2008, which likely represents a fraction of the actual incidents of abuse and neglect.

\section{PTSD in Adolescence}

- The average rate of adolescent PTSD was nearly $14 \%$ among studies conducted in the last decade.

- Rates of PTSD in adolescence are related to type of trauma. Trauma that is associated with more shame and deviance is associated with higher rates of PTSD (e.g., for sexual abuse $57 \%$ have PTSD vs. $10 \%$ for natural disasters).

\section{Risk Factors for PSTD}

- Rates of traumatic exposure peak in adolescence compared to adulthood, which is associated with correspondingly higher rates of PTSD (adult PTSD 7\% vs. adolescent PTSD 13\%).

- Adolescent females are twice as likely to develop PTSD following a significant trauma than males.

- Repeated trauma, regardless of type, heightens the probability of PTSD symptoms and diagnosis.

- Adolescents with less social support are more likely to experience trauma and develop PTSD.
- Serious physical health problems increase risk of PTSD in adolescence.

\section{Correlates of PTSD}

- Adolescents with PTSD are significantly more likely to have failed a grade or to have been suspended than those without PTSD.

- Over $80 \%$ of individuals with PTSD have a comorbid substance-use disorder, typically beginning in adolescence.

- Approximately $6 \%$ of adolescents with PTSD have made a suicide attempt versus less than $2 \%$ for adolescents with no history of trauma or PTSD.

- Brain imaging studies relate PTSD and trauma to differences in emotion regulation, dopamine, and norepinephrine activation.

\footnotetext{
'Department of Psychology, Montclair State University, Montclair, NJ, USA

${ }^{2}$ The Nathan S. Kline Institute for Psychiatric Research, Orangeburg, NY, USA

${ }^{3}$ Department of Pediatrics, Mount Sinai Adolescent Health Center, New York, NY, USA

${ }^{4}$ Department of Child and Adolescent Psychiatry, New York University Langone School of Medicine, New York, NY, USA

${ }^{5}$ National Center for PTSD, Palo Alto Veterans Health Care System, Palo Alto, CA, USA
}

Corresponding Author:

Kate B. Nooner, Department of Psychology, Montclair State University, Montclair, NJ 07043, USA

Email: noonerk@mail.montclair.edu 


\section{Introduction}

Longitudinal research has identified adolescence as a developmental period where youth are particularly susceptible to experiencing trauma and, in turn, developing posttraumatic stress disorder (PTSD) (Breslau, Wilcox, Storr, Lucia, \& Anthony, 2004; Kilpatrick et al., 2003). Adolescence is a developmental period filled with biological, social, and cognitive changes. Adolescents face a number of new developmental demands including developing coherent identities, establishing relations with peers, and developing independence from parents. These changes and transitions may exacerbate risk for PTSD. There may also be specific characteristics of PTSD that have transient developmental counterparts such as avoidance, emotion reactivity, and risk-taking behaviors which are often present in adolescents. For instance, adolescents are more likely than children and adults to engage in a variety of risky behaviors, which may place them at higher risk of developing PTSD. Paralleling these behavioral changes are changes in the adolescent brain that seem to render adolescents more sensitive to the reward value, and therefore less sensitive to the cost, of certain high-risk behaviors (Steinberg, 2008).

At the time of the Diagnostic and Statistical Manual of Mental Disorders - Fourth edition (DSM-IV) PTSD committee report in 1993, only six published studies had reported DSMbased diagnoses of PTSD for children and adolescents (see McNally, 1993). These studies included participants ranging in age from 5 years or less to 18 years. Assessment strategies varied widely and included case studies as well as self-report measures and standardized clinical assessments. Not surprisingly, there was extreme variation in results with rates of PTSD ranging from $0 \%$ to $90 \%$ (McNally, 1993). Since the DSM-IV report, there have been significant advances in the study of PTSD in adolescence, with emphasis on establishing uniform definitions of trauma and systematic use of psychometrically sound assessment instruments. In addition, there has been a steady accumulation of studies that have concentrated specifically on adolescent PTSD.

Although there is recognition that trauma during adolescence creates specific risks for developmental injuries and longterm negative outcomes, extant data on adolescent PTSD is largely missing. Therefore, research on PTSD in adolescence is worthy of its own review. In this review we (a) organize empirical research to illuminate the influence of traumatic events that potentially lead to PTSD, (b) identify risk factors and correlates of PTSD, (c) synthesize research from a variety of studies to better understand how PTSD effects adolescents in a variety of life circumstances, and (d) discuss implications for prevention and intervention programs.

\section{Method}

\section{Criteria for Selection}

The present review utilized PsycINFO, JSTOR, ProQuest, Medline, and PILOTS from January 2000 through December 2011. Search terms included PTSD, abuse, adolescence, adolescent, delinquency, depression, maltreatment, substance use, suicide, terror, trauma, and traumatic events. The articles were published between 2000 and 2011; the PTSD rates during adolescence were from 1993 to 2009. Criteria for inclusion in the review table were studies in which: (1) the mean age of participants fell between 10 and 22 years, (2) a reliable measure of PTSD was used to establish PTSD, consisting of either a structured clinical interview assessing $D S M-I V$ criteria for PTSD, or an empirically validated measure of PTSD in which participants met or exceeded a clinical cutoff, (3) PTSD rates for the participants in the study were stated within the article or obtained through correspondence. All races, ethnicities, cultures, nationalities, and types of trauma were included. Twelve of the 32 studies were conducted in countries other than the United States such as Israel, Turkey, Italy, and China (Dell'Osso et al., 2011a, 2011b; Dixon, Howie, \& Fairbank, 2005; Eksi et al., 2007; Elklit, 2002; Khamis, 2005; Lavi \& Solomon, 2005; Ma et al., 2011; Neugebauer et al., 2009; Schaal \& Elbert, 2006; Seedat, Nyamai, Njenga, Vylhilingum, \& Stein, 2004; Solomon \& Lavi, 2005). Another study examined Native Americans on a reservation with a focus on cultural differences in PTSD (Deters, Novins, Fickenscher, \& Beals, 2006).

\section{Exclusions}

The present review excluded case studies and nonquantitative studies. Studies were also excluded if the mean age of participants fell below 10 or above 22 years. Articles with a focus primarily on children or adults and did not have adolescent specific rates of PTSD were also excluded. In addition, articles that measured partial PTSD or PTSD symptoms without making a diagnosis were excluded from the tables; however, these articles may have been included in the literature review. Finally, articles that were not written in English were also excluded, if translations were not available.

\section{Review Organization}

The content areas that are highlighted in this review of adolescent PTSD emerge from constructs that have been cited in the child PTSD literature as salient but have yet to be specifically tailored to adolescents or are not up-to-date with the current literature (e.g., Pfefferbaum, 1997). In reviews of PTSD in children, factors such as age, gender, family characteristics, developmental level, and biological correlates, emerged as influencing individual responses to trauma and risk of PTSD. In addition, large epidemiological reviews of adult PTSD (e.g., de Girolamo \& McFarlane, 1996) informed the present work, identifying factors such as health problems, repeated trauma, and substance abuse.

\section{Review Characteristics}

In summarizing the rates of PTSD among adolescents, we have grouped studies into eight categories according to specific 
variables related to PTSD: age, gender, repeated trauma, social support, health problems, academic problems, substance abuse, and suicide (See Table 1). The articles in each category specifically focus on how that variable related to PTSD and further elaborated on rates of diagnosis or increased symptomatology of PTSD. Rates of PTSD are also summarized by type of trauma as well as single (e.g., sexual abuse only) versus multiple (e.g., physical abuse, sexual abuse, and witnessed violence) trauma (see Table 2). The purpose of the first table is to illustrate adolescent PTSD rates by risk factors or correlates and the second table shows adolescent PTSD by type of trauma. We also present the emerging literature on biological factors. Since this literature is limited, biological factors were not included in the tables.

\section{Data Extraction and Statistical Methods}

From selected studies, we extracted data sample size, age at assessment, type of trauma, and rate of PTSD (see Tables 1 and 2). Rates reported in this article used weighted averages to adjust for sample size for the means and standard deviations listed in Tables 1 and 2. In cases where information required for analysis was not available in the published study, related publications with the necessary information were utilized or authors contacted (100\% of the reports).

\section{Rates of Trauma and PTSD}

In the United States, $70-80 \%$ of adolescents experienced one or more traumatic events that meet the stressor criterion for PTSD, as defined by the DSM-IV-TR (2000). In order to fit the $D S M-I V-T R$ definition of a stressor of PTSD symptoms, two criteria must be met. First, an individual must see or personally encounter one or multiple events that include either real or threatened death or serious injury to oneself or others. Second, the individual must respond with significant fear, horror, and/or helplessness to this event.

For the purposes of the present review, we will combine terms abuse and assault together within type (physical or sexual) because the type of trauma and the rates of PTSD were very similar in studies of abuse and assault. In addition, perpetrator status was often not designated, and when it was, definitions differed by study or overlapped. This further contributed to the decision to group these types of trauma, which will heretofore be referred to as physical abuse and sexual abuse. Physical abuse differs from physical injury in that physical injury is defined as a trauma resulting in bodily harm that was not caused by the intentional action of another (e.g., being burned from an accidental house fire); so physical injury is grouped under "Threat of Serious Injury" in Table 2.

While research has indicated that the majority of adolescents, approximately 4 of the 5 , meet criteria for exposure to a serious traumatic event, only a fraction of adolescents meet full diagnostic criteria for PTSD (Jaycox, Ebener, Damesek, \& Becker, 2004; Storr, Ialongo, Anthony, \& Breslau, 2007). Of the studies reviewed, the prevalence rate of PTSD ranged from $3 \%$ to $57 \%$; Table 1 represents a summary of the information regarding PTSD in adolescents by variable associated with PTSD (age, gender, repeated trauma, social support, health problems, academic problems, substance abuse, and suicide). In aggregating these groups, the average age of participants is approximately 15 years (mean $=15.9$ years, $S D=2.2$ years) and the rate of PTSD is $13.6 \%(S D=9.1 \%)$.

Type of trauma assessed is represented in Table 2. The most common types of trauma documented in descending order were witnessed violence, natural disaster, and physical abuse. The range of adolescents who develop PTSD aggregated across studies for the types of trauma was between $9 \%$ and $48 \%$ with the highest for sexual trauma (57\%) and the lowest rate related to exposure to natural disasters/other disasters (3\%). Twenty studies did not list the specific types of trauma experienced by participants but stated that participants experienced a significant trauma according to the DSM criteria for PTSD; for these studies, the average rate of PTSD was $10.6 \%(S D=8.2 \%)$

\section{Factors Related to PTSD in Adolescents}

Overall, risk for trauma exposure and PTSD peak in late adolescence. Factors that emerged from the literature as being significantly related to PTSD include age, gender, repeated trauma, social support, health problems, academic problems, substance abuse, and suicide. These factors are discussed in detail in the following sections.

\section{Age}

Research has examined whether age represents a risk or protective factor for PTSD (American Psychiatric Association [APA], 2002; Breslau et al., 2004; Kilpatrick, 2002). Within the literature review, many of the cited articles have focused or noted a relationship between PTSD and age, with older teens in general being at greater risk than younger teens (e.g., Kilpatrick et al., 2003). Ten of the 32 studies have explained the relationship between age and the onset of PTSD (see Table 1: e.g., Breslau et al., 2001; Eksi et al., 2007; Khamis, 2005). For instance, investigations by Breslau et al. (2004) have confirmed that the rates of trauma exposure are higher among teens than adults, but also that rates of PTSD were higher (13\%), nearly double that established for adults $(7 \%$; Breslau et al., 2004). It may be that the ability to cope with a trauma is tenuous during adolescence due to immature nature of cognitive, social, and emotional capacities and less stable social network (APA, Developing Adolescents, 2002). Even though younger teens may be less developed than older teens, the increased exposure to trauma coupled with the prevalence of high-risk activity in later adolescence puts older teens at comparatively greater risk for developing PTSD.

Within the adolescent period, a national household probability sample of adolescents indicated that age was the strongest predictor of increased risk for PTSD (Kilpatrick et al., 2003). Adolescents at the upper end of the study age range, 16- to 17 -year-olds, were at greater risk of experiencing trauma and 
Table I. Table of Variables Associated With PTSD Examined.

\begin{tabular}{|c|c|c|c|c|c|c|}
\hline Author & Year & Age Mean(SD) & Age Range & $N$ & $\begin{array}{l}\text { PTSD } \\
\%(S D)\end{array}$ & $\begin{array}{l}\text { Current or } \\
\text { Lifetime }\end{array}$ \\
\hline \multicolumn{7}{|l|}{ Age } \\
\hline Eksi et al. & 2007 & 14.43 & $9-18$ & 160 & 60 & Current \\
\hline Elklit & 2002 & 14.5 & $13-15$ & 390 & 9 & Current \\
\hline Khamis & 2005 & 14.2 & $12-16$ & 1,000 & 34.1 & Current \\
\hline Macdonald et al. & 2010 & 14.8 & $12-17$ & $\mathrm{I}, 868$ & 8.6 & Current \\
\hline Neugebaurer et al. & 2009 & 15 & $8-9$ & 1,474 & 57.01 & Current \\
\hline Schaal et al. & 2006 & 17.7 & $13-25$ & 68 & 44 & Both \\
\hline Seedat et al. & 2004 & 15.8 & $14-22$ & $2,04 I$ & 14.5 & Current \\
\hline Totals: & & $15.9(2.1)$ & & 13,313 & $16.3(10.3)$ & \\
\hline \multicolumn{7}{|l|}{ Gender } \\
\hline Dixon et al. & 2005 & 16.5 & $13.5-19$ & 100 & 37 & Both \\
\hline Eksi et al. & 2007 & 14.43 & $9-18$ & 160 & 60 & Current \\
\hline Elklit & 2002 & 14.5 & $13-15$ & 390 & 9 & Current \\
\hline Erwin et al. & 2000 & 17.5 & $13.3-22$ & 51 & 18 & Current \\
\hline Jaycox et al. & 2004 & 16.5 & $13-20$ & 212 & 20 & Current \\
\hline Khamis & 2005 & 14.2 & $12-16$ & 1,000 & 34.1 & Current \\
\hline Kilpatrick et al. & 2003 & 14.5 & $12-17$ & 3,906 & 4.8 & Both \\
\hline Lipschitz et al. & 2000 & 15.9 & $13.2-18.5$ & 95 & 23 & Current \\
\hline Lipschitz et al. & 2003 & 17.2 & $|3-2|$ & 104 & 15.2 & Both \\
\hline Ma et al. & 2011 & 18.8 & $12-18$ & 3,208 & 2.5 & Current \\
\hline Macdonald et al. & 2010 & 14.8 & $12-17$ & 1,868 & 8.6 & Current \\
\hline Neugebaurer et al. & 2009 & 15 & $8-9$ & $\mathrm{I}, 474$ & 57.01 & Current \\
\hline Brosky et al. & 2004 & 14.6 & $12-18$ & 152 & 14.5 & Current \\
\hline Deters et al. & 2006 & 15.6 & $13-18$ & 89 & 10 & Lifetime \\
\hline Dixon et al. & 2005 & 16.5 & $13.5-19$ & 100 & 37 & Both \\
\hline Elklit & 2002 & 14.5 & $13-15$ & 390 & 9 & Current \\
\hline Lipschitz et al. & 2000 & 15.9 & $13.2-18.5$ & 95 & 23 & Current \\
\hline Macdonald et al. & 2010 & 14.8 & $12-17$ & 1,868 & 8.6 & Current \\
\hline Neugebaurer et al. & 2009 & 15 & $8-9$ & 1,474 & 57.01 & Current \\
\hline Read et al. & 2011 & 18 & $18-24$ & 3,014 & 9 & Lifetime \\
\hline Schaal et al. & 2006 & 17.7 & $13-25$ & 68 & 44 & Both \\
\hline Seedat et al. & 2004 & 15.8 & $14-22$ & 2,041 & 14.5 & Current \\
\hline Solomon et al. & 2005 & 13.7 & $11.5-15$ & 740 & 18 & Current \\
\hline Totals: & & $15.9(1.7)$ & & $|0,03|$ & $18.5(13.7)$ & \\
\hline \multicolumn{7}{|l|}{ Social Support } \\
\hline Dell'Osso et al. (B) & 2011 & 17.65 & $15-20$ & 475 & 30.7 & Current \\
\hline Eksi et al. & 2007 & 14.43 & $9-18$ & 160 & 60 & Current \\
\hline Elklit & 2002 & 14.5 & $13-15$ & 390 & 9 & Current \\
\hline Erwin et al. & 2000 & 17.5 & $13.3-22$ & 51 & 18 & Current \\
\hline Grasso et al. & 2009 & 10.2 & $6-17$ & 116 & 55 & Both \\
\hline Khamis & 2005 & 14.2 & $12-16$ & 1,000 & 34.1 & Current \\
\hline Kolko et al. & 2010 & 11 & $8-14$ & 1,848 & 11.7 & Current \\
\hline
\end{tabular}


Table I. (continued)

\begin{tabular}{|c|c|c|c|c|c|c|}
\hline Author & Year & Age Mean(SD) & Age Range & $N$ & $\begin{array}{l}\text { PTSD } \\
\%(S D)\end{array}$ & $\begin{array}{l}\text { Current or } \\
\text { Lifetime }\end{array}$ \\
\hline Ma et al. & 2011 & 18.8 & $12-18$ & 3,208 & 2.5 & Current \\
\hline Schaal et al. & 2006 & 17.7 & $13-25$ & 68 & 44 & Both \\
\hline Storr et al. & 2007 & 21 & $19-24$ & 1,698 & 8.8 & Lifetime \\
\hline Totals: & & $14.9(2.6)$ & & 9,083 & I3.I (8.I) & \\
\hline Kean et al. & 2006 & 14.6 & $12-18$ & 158 & 12 & Lifetime \\
\hline Seng et al. & 2005 & 13.3 & $9-17$ & $\mathrm{I}, 025$ & 20.4 & Current \\
\hline Totals: & & I $3.5(0.5)$ & & 1,252 & $19.0(2.3)$ & \\
\hline \multicolumn{7}{|l|}{ Academic Problems } \\
\hline Lipschitz et al. & 2000 & 15.9 & $13.2-18.5$ & 95 & 23 & Current \\
\hline Storr et al. & 2007 & 21 & 19-24 & 1,698 & 8.8 & Lifetime \\
\hline Dixon et al. & 2005 & 16.5 & $13.5-19$ & 100 & 37 & Both \\
\hline Erwin et al. & 2000 & 17.5 & $13.3-22$ & 51 & 18 & Current \\
\hline Kilpatrick et al. & 2003 & 14.5 & $12-17$ & 3,906 & 4.8 & Both \\
\hline Lipschitz et al. & 2000 & 15.9 & $13.2-18.5$ & 95 & 23 & Current \\
\hline Lipschitz et al. & 2003 & 17.2 & $|3-2|$ & 104 & 15.2 & Both \\
\hline Macdonald et al. & 2010 & 14.8 & $12-17$ & 1,868 & 8.6 & Current \\
\hline Totals: & & I4.6 (I.3) & & 9,827 & $5.9(3.8)$ & \\
\hline \multicolumn{7}{|l|}{ Suicide } \\
\hline Dixon et al. & 2005 & 16.5 & $13.5-19$ & 100 & 37 & Both \\
\hline Elklit & 2002 & 14.5 & $13-15$ & 390 & 9 & Current \\
\hline Prinstein et al. & 2008 & $13.5 \mid$ & $12-18$ & 143 & 3.65 & Current \\
\hline Totals: & & $\mid 4.6(0.5)$ & & 633 & $12.2(8.1)$ & \\
\hline
\end{tabular}

Note. PTSD = posttraumatic stress disorder.

Table 2. Trauma Associated With Adolescent PTSD: Listed by Specific Type* As Well As By Single Versus Multiple Type of Trauma

\begin{tabular}{lcc}
\hline Type & $\begin{array}{c}\text { Number } \\
\text { of Studies }\end{array}$ & $\begin{array}{c}\text { \% PTSD } \\
\text { Mean (SD) }\end{array}$ \\
\hline Witnessed Violence a & 11 & $18.3(7.8)$ \\
Natural disaster/other disaster & 8 & $8.6($ II.5) \\
Physical abuse & 6 & $14.8(6.4)$ \\
Sexual abuse & 5 & $48(3.8)$ \\
Physical injury & 5 & $29.1(8.0)$ \\
Threat of serious injury & 4 & $13(9.1)$ \\
Significant trauma (type unspecified) & 20 & $10.6(8.2)$ \\
Single & 10 & $25.7(10.4)$ \\
Multiple & 29 & $9.7(6.1)$ \\
\hline
\end{tabular}

Note.*Studies may ask about more than one type of trauma.

${ }^{a}$ Domestic or community.

developing PTSD than those at the lower end of the age range, 12- to 13-year-olds. In keeping with these findings, epidemiologic investigations of trauma exposure and PTSD among urban youth also reported that the rates of exposure to traumatic events and PTSD peak at 16-17 years of age (Breslau et al., 2004; Neugebauer et al., 2009). These elevated rates of PTSD in late adolescence are significantly higher than those at either early adolescence or young adulthood and are positively related to rates of PTSD as well as comorbidities such as depression or substance abuse (Macdonald et al., 2010; Neugebauer et al., 2009).

\section{Gender}

Gender differences are commonly associated with PTSD with females typically having higher rates of PTSD than males (Kessler, Sonnega, Bromet, Hughes, \& Nelson, 1995). Within this review, four studies examined only females (Brosky \& Lally, 2004; Dixon et al., 2005; Lipschitz, Rasmusson, Anyan, \& Cromwell, 2000; Lipschitz et al., 2003), one examined only males (Eksi et al., 2007). Twenty-two of the 32 articles reviewed have noted a relationship between PTSD and gender (see Table 1: e.g., Breslau et al., 2004; Brosky \& Lally, 2004; 
Elklit, 2002). Similar to that in adult populations (Kessler et al., 1995), a common finding in adolescence is that while males and females experience an equal number of traumatic events, adolescent females are typically twice as likely to develop PTSD (Breslau et al., 2004; Brosky \& Lally, 2004; Elklit, 2002; Kilpatrick et al., 2003; Read et al., 2011; Reeybe et al., 2000). Furthermore, adolescent females have been found to be at greater risk for PTSD-related cognitions following trauma, indicating that they had more lasting negative views of the world and themselves (Ma et al., 2011). These cognitive factors were found to be strong predictors of PTSD diagnosis for both males and females, with the effect being especially strong for females who were more likely to have the cognitions.

The most common types of trauma experienced by adolescent males and females are the same: witnessed violence, followed by physical or sexual victimization. While the types of trauma adolescents experience may be the same, the results of this review have revealed differences in rates of PTSD by gender; however, these findings are inconsistent. Some studies found that males are more likely to experience trauma than females $(87.2 \%$ for males vs. females for $78.4 \%)$. Adolescent males also experience more trauma overall with 2.7 traumatic exposures per year versus 1.9 traumatic exposures for females (Breslau et al., 2004; Seedat et al., 2004; Zona \& Milan, 2011). Others have found that females are more likely than males to experience traumas, such as rape and sexual assault, 75\% versus $51.3 \%$, respectively (Brosky \& Lally, 2004). Gender differences like these appear even more pronounced in specialized samples, such as in psychiatric inpatient or forensic settings but caution should be taken in interpreting these findings as sample sizes tended to be small (e.g., Lipschitz et al., 2003). However, even after controlling for frequency and type of event, rates of PTSD are still greater in adolescent females than males (Breslau et al., 2004; Doran \& Dogan, 2011; Larmarca et al., 2010; Zona \& Milan, 2011).

When comparing, comorbidity rates for females and males, the data indicate that rates among females are nearly twice that of males $(6.3 \%$ vs. 3.7\%; Kilpatrick et al., 2003; Macdonald et al., 2010). Females were 3 times as likely to have PTSD and a major depressive disorder (MDD) and were twice as likely as males to have PTSD, MDD, and/or substance abuse/dependence (SA/D). It is important to note that beyond gender differences, a comorbidity of MDD appears to be quite common for both males and females suffering with PTSD, even though it is more common among females.

\section{Repeated Trauma}

Although there is clear evidence that a single exposure to a traumatic event is sufficient for developing PTSD, researchers are interested in whether repeated instances of trauma increase the likelihood of a PTSD diagnosis during adolescence (Finkelhor et al., 2007a, 2007b). Repeated instances of trauma have been associated with higher risk for a range of psychopathology including but not limited to PTSD and MDD (MacDonald et al., 2010). Independent of type of trauma,
11 articles found that exposure to repeated traumas put adolescents at heightened risk of developing PTSD symptoms (See Table 1: e.g., Deters et al., 2006; Elklit, 2002, MacDonald et al., 2010). Many adolescents face this risk since repeated trauma is common, with a significant proportion of teens (approximately one in five) experiencing six or more traumatic events during adolescence (Deters et al., 2006). Adolescents who have had six or more traumatic exposures were significantly more likely to fit Criterion C and Criterion D than those with one or two exposures (Deters et al., 2006). In addition to having more clinical symptoms associated with PTSD, adolescents with six or more traumatic exposures also reported greater severity of PTSD symptoms, particularly related to avoidance and arousal.

In addition to the increased severity of PTSD symptoms, there is also evidence that repeated trauma is related to greater chances of receiving a PTSD diagnosis. Exposure to more trauma during adolescence as reported on the Trauma Symptom Checklist was related to greater probability of PTSD diagnosis (Seedat et al., 2004). Greater exposure to traumatic events and heightened feelings of danger also lead to more PTSD symptoms according the to Global Symptom Severity measure (Solomon \& Lavi, 2005). Studies that focused on adolescent female offenders also indicated that those with PTSD diagnoses reported greater exposure to different types of traumas. Adolescent female offenders meeting full criteria for PTSD reported on average 4.7 traumatic events, compared to 3.2 events for partial PTSD diagnosis, and 2.4 events for those with no diagnosis (Lipshitz et al., 2000). These results have been replicated with adolescents in inpatient psychiatric and juvenile justice settings (Dixon et al., 2005; Lipschitz et al., 2003). While exposure to repeated trauma seems to be more common in specialized settings (e.g., juvenile justice) than community settings, repeated trauma still emerges as a salient risk factor of PTSD for adolescents regardless of setting (Finkelhor et al., 2007a, 2007b).

\section{Social Support}

Social support from parents, peers, and others has been found to be a protective factor both before and after a trauma (Collishaw et al., 2007; Lee, Detels, Rotheram-Borus, \& Duan, 2007; Maschi, 2006; Ozer \& Weinstein, 2004). Eleven of the 32 studies found strong relationships between PTSD and social support (See Table 1: e.g., Eksi et al., 2007; Elkit et al., 2002; Grasso et al., 2009; Ma et al., 2011). A possible mechanism for this relationship may be that having positive social support decreases the chances that adolescents will engage in the risky behavior that leads to trauma; as well as the reverse, where negative social support increases the chances that adolescents will engage in risky behavior that leads to trauma (Collishaw et al., 2007). Therefore, social support may partially mediate the relationship between risky behavior and trauma. In a longitudinal epidemiological study that followed 571 individuals from adolescence into adulthood, adolescents reporting physical or sexual abuse were found to be resilient as adults if they had 
stable, nurturing relationships with parents, friends, and partners. Resilience was operationalized as experiencing physical and/or sexual abuse and being free of psychiatric symptoms for 30 years following the abuse. After controlling for severity of abuse, those designated as resilient were less likely to experience recurrent PTSD or related comorbidities such as, depression, suicidal behavior, and substance abuse (Collishaw et al., 2007).

The support and positive influence of a stable parent or caregiver has also been empirically demonstrated as improving the natural course of recovery from PTSD (Breslau et al., 1991). As a result, parents or caregivers have been routinely incorporated into treatment interventions (see Cohen, Mannarino, Berliner, \& Deblinger, 2000). While parental support is vital for PTSD prevention and recovery, for many traumatized adolescents, this support is significantly compromised due to parental substance abuse problems, untreated mental health problems, significant morbidity and early mortality, variable presence related to residence instability, and prison sentences (see Lee et al., 2007; Ozer, 2005). Overall, results indicated that feeling positively supported by at least one parent and having age appropriate peer relationships predicted recovery from PTSD among physically or sexually abused youth. Furthermore, these factors exert a more substantial positive impact when they occurred consistently over time (Ozer, 2005).

While long-term social support is important, findings suggest that initial positive social support can also build resilience in adolescents following trauma (Maschi, 2006; Ozer \& Weinstein, 2004). A 6-month follow-up study of sexually abused adolescent girls found that social support immediately following trauma was correlated with decreases in internalizing symptoms including those related to avoidance and withdrawal (Bal, De Bourdeaudhuij, Crombez, \& Van Oost, 2005). In a nationally representative sample of adolescent boys who had experienced violence (e.g., witnessed violence, physical assault, and sexual assault), positive social support following trauma reduced the risk of delinquency and violent behaviors (Maschi, Bradley, \& Morgan, 2008). In contrast, research has revealed that negative social support (e.g., criticism, blaming responses) or a lack of social support immediately following trauma was associated with increased rates of adolescent depression and other negative outcomes (Bal et al., 2005; Lee et al., 2007). For example, among the most vulnerable adolescents, such as those who are HIV-affected, negative social support following trauma was significantly associated with increased rates of adolescent depression, lower self-esteem, and conduct problems (Lee et al., 2007). Loss of social support was also found to be related to higher rates of PTSD; adolescents who had recently lost someone close to them were among the most vulnerable to repeating trauma and developing PTSD (Dell'Osso, 2011b).

While these findings show the differential impact of positive versus negative social support on psychological functioning, it is possible that one of the factors influencing whether an adolescent receives positive or negative social support is the type of trauma. For example, adolescents who are sexually assaulted may be blamed for their role in "causing" the trauma, which can contribute to the stigma and shame that put these youth at increased risk for negative outcomes (Charuvastra \& Cloitre, 2008). In contrast, adolescents who live through a natural disaster are more likely to receive positive support and be regarded as "survivors," which may reduce risk of negative outcomes by fostering positive self-esteem following a trauma (Finkelhor, Ormrod \& Turner, 2007b). Therefore, the differential impact of positive and negative social support and the relationship of type of trauma to social support are worthy of further exploration in the etiology of PTSD in adolescence.

\section{Health Problems}

Few studies have considered the physical health consequences of PTSD in adolescence. Within this review three articles specifically examined physical health issues and how they relate to PTSD (See Table 1: Fein et al., 2002; Kean, Kelsay, Wamboldt, \& Wamboldt, 2006; Seng, Graham-Bermann, Clark, McCarthy, \& Ronis, 2005). Longitudinal research has indicated that $37.5 \%$ of adolescents with a PTSD diagnosis rated their health as poor, which was significantly higher than adolescents with trauma history but no PTSD diagnosis at $21.3 \%$ and adolescents with no trauma history or PTSD diagnosis at $10 \%$ (Giaconia et al., 1995). Data from a large crosssectional study of teenage females also found that having a PTSD diagnosis in adolescence was associated with poorer health outcomes, in particular more chronic conditions and reproductive health problems (Seng et al., 2005). Specifically, adolescent females with PTSD were 3 times more likely to have asthma, 5 times more likely to have irritable bowel syndrome, and twice as likely to have a sexually transmitted disease (Seng et al., 2005). Patterns of adverse health problems and PTSD in adolescence were similar to that of adult women with PTSD, suggesting that the health problems associated with PTSD in adolescence may continue in adulthood. Most of the literature examining the relationship of PTSD and health problems focused on adolescent females; therefore, studies examining these relationships in adolescent boys are needed to fill this gap in the literature.

\section{Academic Problems}

Although only two articles specifically examine academic problems in relation to PTSD, the data provide compelling support that poorer academic performance and lower intellectual functioning are correlates of PTSD in adolescence (See Table 1: Breslau et al., 2004; Lipschitz et al., 2000; Silva et al., 2000; Storr et al., 2007). Compared to traumatized adolescents without PTSD, those with PTSD were significantly more likely to have failed a grade in school or to have been suspended (Lipschitz et al., 2000). In contrast, youth with poorer academic performance in childhood were more likely to experience trauma and develop PTSD in adolescence (Breslau et al., 2004; Storr et al., 2007). Rates of PTSD were 
significantly higher among adolescents who were rated by their teachers as having concentration problems in elementary school. Conversely, better academic performance was also found to be a potential protective factor. Compared to those in the lowest quartile, children with the highest readingreadiness scores in elementary school were less likely to experience trauma or develop PTSD in adolescence (Storr et al., 2007).

The effects of intellectual functioning in early childhood seem to extend into adolescence in that higher intelligence in childhood decreases risk of PTSD in adolescence (Storr et al., 2007). Specifically, those with at least high average intellectual functioning (i.e., IQ scores at least $1 S D$ above the population mean) in the first grade were at lower risk for exposure to traumatic events as well as developing PTSD by age 17 (Storr et al., 2007). While higher IQ scores appeared protective against PTSD, lower than average IQ scores were not found to increase risk of developing PTSD. Although a relationship between intellectual functioning and PTSD exists across development, the mechanisms that underlie this relationship are still unclear. Storr and colleagues (2007) suggest that people with higher IQs may be better equipped to avoid potentially traumatic events and in turn are less likely to develop PTSD. It is also possible that people with better intellectual functioning have greater ability to respond adaptively after experiencing trauma, which reduces their chances of developing PTSD.

\section{Substance Abuse}

As in adulthood, the potential causal relationships among trauma history, PTSD, and substance abuse are complex. The study of substance abuse among adolescents has primarily focused on the negative consequences of substance abuse such as delinquency, criminal behaviors, sexual risk behaviors, and suicidal behaviors (Jaycox et al., 2004; Schumacher et al., 2006; Vega et al., 2002). In contrast, the antecedents of adolescent substance abuse have received less attention. However, consistent with the adult study outcomes (see Stewart, 1996), it seems that substance abuse is more strongly related to having prior PTSD symptoms than a specific traumatic event or its characteristics (e.g., type, severity; Cisler et al., 2010; Kilpatrick et al., 2003).

Within this review, five studies specifically examined the relationship between PTSD and substance abuse; substances specifically examined included nicotine, alcohol, or marijuana (See Table 1: Deters et al., 2006; Jaycox et al., 2004; Kilpatrick et al., 2003; Lipschitz et al., 2003). Two other studies included a measure of substance abuse in relation to PTSD but did not ask about specific substances (Dixon et al., 2005; Lipschitz et al., 2000). Regardless, almost all point to the fact that PTSD in adolescence is associated with increased rates of substance abuse (Deters et al., 2006; Jaycox et al., 2004; Kilpatrick et al., 2003; Lipschitz et al., 2000, 2003; Macdonald et al., 2010).

The National Comorbidity Survey (NCS, Kessler, 2000), an epidemiological survey of mental disorders in Americans aged 15-54, demonstrated that over $80 \%$ of individuals with PTSD had a lifetime history of one or more comorbid Axis I diagnoses. The NCS also established that traumatic events and PTSD were especially common in the United States, with about one in ten $(11 \%)$ of those surveyed experiencing four or more severe traumas over the course of their lifetime. Therefore, given the high rates of traumatic events and the established rates of comorbidity, the risk of SA/D among those who have experienced trauma is also high. One explanation for these findings is that history of trauma, including physical and sexual abuse during adolescence, is a common factor for PTSD as well as substance-use disorders (Deters et al, 2006; Duncan, Alpert, Duncan, \& Hops, 1997; Hanson et al, 2001; Schumacher, 2006). Alcohol use disorders were among the most common comorbidities, occurring in 30-50\% of adolescents with PTSD. Other investigations of trauma-exposed adolescents (Kilpatrick et al., 2003; Macdonald et al., 2010) also reported that comorbidity among PTSD, most often substance abuse and/or depression, occurred more commonly than PTSD alone. In assessing the relationship between PTSD and substance abuse per se, Kilpatrick and colleagues (2000) assessed a nationally representative sample of 4,023 adolescents, aged $12-17$, for risk of $D S M$-based substance abuse and dependence disorders associated with PTSD related to sexual assault (including sexual abuse), physical assault (including physical abuse), and witnessing violence. The study controlled for the effects of age, gender, race and parental substance abuse, which are factors known to influence substance abuse. The influence of the identified traumatic stressor and any other trauma experienced by the study participant was also controlled. Results indicated that PTSD independently increased the risk of marijuana and hard-drug use (e.g., methamphetamine, heroine). No gender differences were observed in any of the major multivariate analyses related to trauma history or PTSD status, supporting the conclusion that traumatized and PTSD positive adolescent males and females were equally likely to develop substance abuse problems. On average, trauma history preceded substance-use history. The average age of first victimization by sexual and/or physical abuse was 11.6 years, with the average onset of substance use was between 13.1 and 14.8 years, depending on the substance. Therefore, trauma, PTSD, and substance use are highly interrelated, persistent, debilitating, and are likely to emerge during adolescence when it is developmentally normative to take risks and experiment with substances (Breslau et al., 2001; Dahl et al., 2004). Consequently, those developing targeted interventions for adolescents should consider incorporating a substance abuse component into treatment or prevention efforts. In addition, interventions that rule out adolescents who are substance users should consider the generalizability of findings given the high rates of comorbid PTSD and substance-use disorders (Kilpatrick et al., 2003).

\section{Suicide}

Suicide is a leading cause of death among adolescents aged 15-19 (see Mazza, 2000). Several studies have identified the 
increased prevalence of suicide attempts among adolescents with PTSD, even after controlling for trauma history (Kandel, Raveis, \& Davies, 1991; Miranda et al., 2008; Prinstein, Nock, Spirito, \& Grapentine, 2001; Wichstrom, 2000). Among the studies included in this review, three found that suicide attempts were correlated with PTSD (See Table 1: Dixon et al., 2005; Elklit et al., 2002; Prinstein, Nock, Simon, \& Aikens, 2008). This corroborates earlier research which found that $33 \%$ of adolescents with PTSD reported suicidal ideation compared to $18 \%$ of traumatized adolescents without PTSD and $11 \%$ of those never traumatized (Giaconia et al., 1995). Eighteen percent (18\%) of adolescents with PTSD reported having made a suicide attempt compared to $5.7 \%$ of those with a trauma and no PTSD and $1.8 \%$ with no trauma or PTSD (Giaconia et al., 1995). More than 1 in 6 PTSD adolescents, compared with less than 1 in 55 of the never traumatized group, reported at least one suicide attempt by age 18 (Giaconia et al., 1995). Adolescents with PTSD were also at significantly greater risk for suicide attempts than those without PTSD, even if they had experienced trauma. No gender differences were obtained.

Two community studies of high school students found that PTSD symptomatology was a predictor of both suicidal ideation and suicide attempts, even after controlling for factors such as depression, violence exposure, gender, and age (Mazza, 2000; Mazza \& Reynolds, 1999). These data indicate that PTSD symptomatology is uniquely related to adolescent suicidality and thus should be included as a recognized suicide risk factor and target of intervention.

\section{Biological Factors}

Studies of neurological and cognitive factors related to adolescent development indicate that capacities imperative to higher level brain functioning develop during adolescence (Blakemore \& Choudhury, 2006; Giedd et al., 1999; Lenroot \& Giedd, 2006; Paus, 2005) and these vital capacities may be derailed by PTSD (DeBellis et al., 2002, 2010). Well-established neurological developmental milestones that occur during adolescence include increases in white matter (Giedd et al., 1999; Lenroot \& Giedd, 2006; Paus, 2005) and changes in gray matter, with the most rapid changes between the 12 and 20 years of age (Giedd et al., 1999; Lenroot \& Giedd, 2006). In addition, brain structures that have been linked to PTSD, such as those involved in emotion regulation and memory (e.g., amygdala and hippocampus), also substantially increase in volume during adolescence (Paus, 2005).

Research of the neurological changes associated with trauma and PTSD symptoms over the course of childhood and adolescence is still in its relative infancy, yet important discoveries have been made (Carrion et al., 2001; DeBellis et al., 1999). DeBellis and colleagues (2002) note that stress activates norepinephrine and dopamine in the prefrontal cortex, which acts as protective measure for psychological health. However, severe stress can result in a shutdown of crucial frontal inhibition capacities and is related to decreased brain volumes in youth with PTSD symptoms (DeBellis et al., 2002). Structural neuroimaging research has demonstrated that frontal regions, which mature rapidly during adolescence and are vital for higher order cognitive functioning, are also impacted by trauma (Carrion et al., 2001). The long-term side effects of the neurological changes associated with PTSD during adolescence are still largely unknown but have been linked to disorders such as attention-deficit hyperactivity disorder and conduct disorder (DeBellis et al., 1999, 2002).

The hippocampus plays a vital role in inhibition and memory, capacities that are central in helping individuals navigate away from potentially traumatic situations (Giedd et al., 1999). Neuroimaging research has provided evidence that PTSD is related to hippocampal atrophy among adults (Sapolsky, 2000). Functional neuroimaging studies show promise for revealing consistent findings for adolescents with PTSD that have been illusive in structural neuroimaging research (DeBellis et al., 2003). To date, neuroimgaging studies have revealed functional alterations to the hippocampus that are associated with a diagnosis of PTSD during adolescence (Giedd et al., 1999; Lenroot \& Giedd, 2006; Paus, 2005). In particular, the hippocampus of adolescents with PTSD appears to function more like the hippocampus of a child (i.e., it functions more immaturely). While neuroimaging research has revealed some novel and exciting findings regarding the deleterious biological implications associated with PTSD during adolescence, vastly more work is needed in this area.

\section{Recommendations}

Adolescence is a developmental period where exposure to trauma reaches its peak (Breslau et al., 2004) and as such it is a critical time for interventions aimed at preventing PTSD and curtailing sequallae. While some risk factors are well established, such as exposure to repeated trauma, others such as brain-related changes associated with trauma and PTSD symptoms are still emerging. This review has demonstrated that there are a range of identifiable risk factors and correlates that researchers and clinicians can address in designing interventions for PTSD in adolescence. The following recommendations are intended for those working on the front lines, specifically intervention researchers, clinicians, policy makers, and parents.

First, to protect youth during late adolescence, preventive interventions should be targeted toward those of middleschool age. Targeting youth in middle school is suggested because this age is proximal to the highest risk period for PTSD. Prevention efforts focused on middle school youth have the advantage of being tailored to the specific experiences youth will encounter in late adolescence, material that may not be appropriate with younger children. In addition, interventions can be internalized just before the period of greatest risk, maximizing retention of information as well as opportunity for successful application.

Second, including and educating parents and educators about the specific interventions will further promote the 
effectiveness of the interventions. As this review has demonstrated, that social support particularly from stable, nurturing adults is beneficial to adolescents who have experienced trauma (Cohen et al., 2010).

Third, gender should be considered in designing interventions. Although both males and females develop PTSD in adolescence, risk of PTSD is higher in females. Mixed gender interventions may be appropriate in some cases (e.g., treatment following a natural disaster) while in others, (e.g. sexual trauma), gender specific interventions may be warranted.

Fourth, interventions should either be trauma specific and/or target youth who are likely to have experienced cumulative or complex trauma. Certain types of trauma, including sexual abuse, sexual assault and rape, as well as chronic trauma place adolescents at increased risk of developing PTSD; therefore, tailoring services to these areas is needed.

Fifth, interventions should assess and target adolescents where PTSD is likely to be comorbid with other psychopathology, in particular SA/D and MDD. Often, randomized trials of interventions rule out participants with comorbid diagnoses. However, with PTSD, comorbidity is the norm rather than the exception. A first step might be to design interventions that target PTSD and SA/D or PTSD and MDD/suicide since these are commonly co-occurring among adolescents who carry a PTSD diagnoses. A successful intervention that targets these comorbid disorders has the potential to decrease the lifelong prevalence of these disorders.

Finally, interventions should be aimed at improving the capacity of youth to effectively regulate emotion and appropriately interact in interpersonal contexts (Keenan, 2000). Emotion-focused intervention could protect youth from some of the most salient risk factors for trauma and PTSD including: revictimization, comorbidity, as well as transmission to future generations (Levitt, Malta, Marin, Davis \& Cloitre, 2007). Giving youth skills to build positive relationships, strengthen areas of social support, avoid high-risk situations, and apply positive coping skills should decrease trauma exposure and increase resilience among adolescents.

In summary, PTSD in adolescence is debilitating in many aspects of life as seen in the research demonstrating measurable behavioral and brain changes as well as increased instances of substance abuse and suicide. For all of these reasons, understanding the diverse factors that relate to the development, maintenance, and recovery from PTSD is especially important for protecting adolescents, which this review has shown is a unique and vulnerable population.

\section{Implications for Practice, Policy, and Research}

- Clinicians and researchers should routinely assess adolescents for PTSD given its prevalence during this developmental period.

- To protect adolescents with trauma histories from repeated trauma and developing full-blown PTSD, it will be important to have an adult as a positive source of social support.
- Educating parents, as well as working with teens directly, will be especially important in achieving these goals.

\section{Declaration of Conflicting Interests}

The authors declared no potential conflicts of interest with respect to the research, authorship, and/or publication of this article.

\section{Funding}

The authors received no financial support for the research, authorship, and/or publication of this article.

\section{References}

American Psychiatric Association. (2000). Diagnostic and statistical manual of mental disorders (4th ed., text rev.). Washington, DC: Author.

Anda, R. F., Fleisher, V. I., Felitti, V. J., Edwards, V. J., Whitfield, C. L., Dube, S. R., \& Williamson, D. F. (2004). Childhood abuse, household dysfunction and indicators of impaired worker performance in adulthood. Permanente Journal, 8, 30-38.

Bal, S., De Bourdeaudhuij, I., Crombez, G., \& Van Oost, P. (2005). Predictors of trauma symptomatology in sexually abused adolescents: A 6-month follow-up study. Journal of Interpersonal Violence, 20, 1390-1405.

Bayer, C. P., Klasen, F., \& Adam, H. (2007). Association of trauma and PTSD symptoms with openness to reconciliation and feelings of revenge among former Ugandan and Congolese child soldiers. Journal of American Medical Association, 298, 555-559.

Blakemore, S. J., \& Choudhury, S. (2006). Development of the adolescent brain: Implications for executive function and social cognition. Journal of Child Psychology and Psychiatry, 47, 296-312.

Breslau, N., Davis, G. C., Andreski, P., \& Peterson, E. (1991). Traumatic events and posttraumatic stress disorder in an urban population of young adults. Archives of General Psychiatry, 48, 216-222.

Breslau, N., Johnson, E. O., Hiripi, E., \& Kessler, R. C. (2001). Nicotine dependence in the United States: Prevalence, trends, and smoking persistence. Archives of General Psychiatry, 58, 810-816.

Breslau, N., Wilcox, H. C., Storr, C. L., Lucia, V. C., \& Anthony, J. C. (2004). Trauma exposure and posttraumatic stress disorder: A study of youths in urban America. Journal of Urban Health, 81, 530-544.

Brosky, B. A., \& Lally, S. J. (2004). Prevalence of trauma, PTSD, and dissociation in court-referred adolescents. Journal of Interpersonal Violence, 19, 801-814.

Carrion, V. G., Weems, C. F., Eliez, S., Patwardhan, A., Brown, W., Ray, R. D., et al. (2001). Attenuation of frontal asymmetry in pediatric posttraumatic stress disorder. Biological Psychiatry, 50, 943-951.

Charuvastra, A., \& Cloitre, M. (2008). Social bonds and posttraumatic stress disorder. Annual Review of Psychology, 59, 301-328.

Cisler, J. M., Amstadter, A. B., Begle, A. M., Resnick, H. S., Danielson, C. K., Saunders, B. E., et al. (2011). PTSD symptoms, potentially traumatic event exposure, and binge drinking: A prospective study with a national sample of adolescents. Journal of Anxiety Disorders, 25, 978-987. 
Cloitre, M., Tardiff, K., Marzuk, P. M., Leon, A. C., \& Potera, L. (1996). Childhood abuse and subsequent sexual assault among female inpatients. Journal of Traumatic Stress, 9, 473-482.

Cohen, J. A., Mannarino, A. P., Berliner, L., \& Deblinger, E. (2000). Trauma-focused cognitive behavioral therapy for children and adolescents: An empirical update. Journal of Interpersonal Violence, 15, 1202-1223.

Collishaw, S., Pickles, A., Messer, J., Rutter, M., Shearer, C., \& Maughan, B. (2007). Resilience to adult psychopathology following childhood maltreatment: Evidence from a community sample. Child Abuse \& Neglect, 31, 211-229.

Davidson, J. R.T., \& Fairbank, J. A. (1993). The epidemiology of posttraumatic stress disorder. In J. R. T. Davidson \& E. Foa (Eds.), Posttraumatic stress disorder: DSM-IV and beyond (pp. 147169). Washington, DC: American Psychiatric Press.

DeBellis, M. D., Hooper, S. R., Woolley, D. P., \& Shenk, C. E. (2010). Demographic, maltreatment, and neurobiological correlates of PTSD symptoms in children and adolescents. Journal of Pediatric Psychology, 35, 570-577.

DeBellis, M. D., Keshavan, M. S., Shifflet, H., Iyengar, S., Beers, S.R., Hall, J., et al. (2002). Brain structures in pediatric maltreatment-related posttraumatic stress disorder: a sociodemographically matched study. Biological Psychiatry, 52, 1066-1078.

DeBellis, M. D., Keshavan, M. S., Clark, D. B., Casey, B. J., Giedd, J., Boring, A. M., et al. (1999b). A.E. Bennett Research Award. Developmental traumatology part II: Brain development. Biological Psychiatry, 45, 1271-1284.

de Girolamo, G., \& McFarlane, A. C. (1996). The epidemiology of PTSD: A comprehensive review of the international literature. In A. J. Marsella, M. J. Friedman, E. T. Gerrity, \& R. M. Scurfield (Eds), Ethnocultural aspects of posttraumatic stress disorder: Issues, research, and clinical applications (pp. 33-85). Washington, DC, US: American Psychological Association.

Dell'Osso, L., Carmassi, C., Massimetti, G., Conversano, C., Daneluzzo, E., Riccardi, L., et al. (2011b). Impact of traumatic loss on post-traumatic spectrum symptoms in high school students after the l'Aguila 2009 earthquake in Italy. Journal of Affective Disorders, 134, 59-64.

Dell'Osso, L., Carmassi, C., Massimetti, G., Daneluzzo, E., Di Tommaso, S., \& Rossi, A. (2011a). Full and partial PTSD among young adult survivors 10 months after the 1'Aguila 2009 earthquake: Gender differences. Journal of Affective Disorders, 131, 79-83.

Deters, P. B., Novins, D. K., Fickenscher, A., \& Beals, J. (2006). Trauma and posttraumatic stress disorder symptomatology: Patterns among American Indian adolescents in substance abuse treatment. American Journal of Orthopsychiatry, 76, 335-345.

Dixon, A., Howie, P., \& Starling, J. (2005). Trauma exposure, posttraumatic stress, and psychiatric comorbidity in female juvenile offenders. Journal of the American Academy of Child \& Adolescent Psychiatry, 44, 798-806.

Dogan, A. (2011). Adolescents' posttraumatic stress reaction and behavior problems following Maramara earthquake. European Journal of Psychotraumatology, 2, 5825.

Doran-Lamarca, S., Vogt, D. S., King, D. W., King, L. A., \& Saxe, G. N. (2010). Pretrauma problems, prior stressor exposure, and gender as predictors of change in posttraumatic stress symptoms among physically injured children and adolescents. Journal of Consulting and Clinical Psychology, 78, 781-793.

Duncan, S. C., Alpert, A., Duncan, T. E., \& Hops, H. (1997). Adolescent alcohol use development and young adult outcomes. Drug \& Alcohol Dependence, 49, 39-48.

Eksi, A., Braun, K. L., Ertem-Vehid, H., Peyerli, G., Saydam, R., Toparlak, D., \& Alyanak, B. (2007). Risk factors for the development of PTSD and depression among child and adolescent victims following a 7.4 magnitude earthquake. International Journal of Psychiatry in Clinical Practice, 11, 190-199.

Elklit, A. (2002). Victimization and PTSD in a Danish national youth probability sample. Journal of the American Academy of Child \& Adolescent Psychiatry, 41, 174-181.

Erwin, B. A., Newman, E., McMackin, R. A., Morrissey, C., \& Kaloupek, D. G. (2000). PTSD, malevolent environment, and criminality among criminally involved male adolescents. Criminal Justice and Behavior, 27, 196-215.

Fein, J. A., Kassam-Adams, N., Gavin, M., Huang, R., Blanchard, D., \& Datner, E. M. (2002). Persistence of posttraumatic stress in violently injured youth seen in the emergency department. Archives of Pediatrics \& Adolescent Medicine, 156, 836-840.

Finkelhor, D., Ormrod, R. K., \& Turner, H. A. (2007a). Polyvictimization and trauma in a national longitudinal cohort. Development and Psychopathology, 19, 149-166.

Finkelhor, D., Ormrod, R. K., \& Turner, H. A. (2007b). Revictimization patterns in a national longitudinal sample of children and youth. Child Abuse \& Neglect, 31, 479-502.

Giaconia, R. M., Reinherz, H. Z., Silverman, A. B., Pakiz, B., Frost, A. K., \& Cohen, E. (1995). Traumas and posttraumatic stress disorder in a community population of older adolescents. Journal of the American Academy of Child \& Adolescent Psychiatry, 34, 13691380.

Gidycz, C. A., Coble, C. N., Latham, L., \& Layman, M. J. (1993). Sexual assault experiences in adulthood and prior victimization experiences. Psychology of Women Quarterly, 17, 151-168.

Gidycz, C. A., Hanson, K., \& Layman, M. J. (1995). A prospective analysis of the relationships among sexual assault experiences. Psychology of Women Quarterly, 19, 5-29.

Giedd, J. N., Blumenthal, J., Jeffries, N. O., Castellanos, X., Liu, H., Zijdenbos, A., et al. (1999). Brain development during childhood and adolescence: A longitudinal MRI study. Nature Neuroscience, 2, 861-863.

Goenjian, A. K., Roussos, A., Steinberg, A. M., Sotiropoulou, C., Walling, D., Kakaki, M., et al. (2011). Longitudinal study of PTSD, depression, and quality of life among adolescents after the Parnitha earthquake. Journal of Affective Disorders, 133, 509-515.

Grasso, D., Boonsiri, J., Lipschitz, D., Guyer, A., Houshya, S., Douglas-Palumberi, H., et al. (2009). Posttraumatic stress disorder: The missed diagnosis. Child Welfare, 88, 157-176.

Horowitz, K., Weine, S., \& Jekel, J. (1995). PTSD symptoms in urban adolescent girls: Compounded community trauma. Journal of the American Academy of Child \& Adolescent Psychiatry, 34, 13531361.

Jaycox, L. H., Ebener, P., Damesek, L., \& Becker, K. (2004). Trauma exposure and retention in adolescent substance abuse treatment. Journal of Traumatic Stress, 17, 113-121. 
Kandel, D. B., Raveis, V. H., \& Davies, M. (1991). Suicidal ideation in adolescence: Depression, substance abuse, and other risk factors. Journal of Youth and Adolescence, 20, 289-309.

Kean, E. M., Kelsay, K., Wamboldt, F., \& Wamboldt, M. Z. (2006). Posttraumatic stress in adolescents with asthma and their parents. Journal of the American Academy of Child \& Adolescent Psychiatry, 45, 78-86.

Keenan, K. (2000). Emotion dysregulation as a risk factor for child psychopathology. Clinical Psychology: Science and Practice, 7, 418-434.

Kessler, R. C. (2000). Posttraumatic stress disorder: The burden to the individual and society. Journal of Clinical Psychiatry, 61, 4-12.

Kessler, R. C., Avenevoli, S., \& Merikangas, K. R. (2001). Mood disorders in children and adolescents: An epidemiologic perspective. Society of Biological Psychiatry, 49, 1002-1014.

Kessler, R. C., Sonnega, A., Bromet, E., Hughes, M., \& Nelson, C. B. (1995). Posttraumatic stress disorder in the national comorbidity survey. Archives of General Psychiatry, 52, 1048-1060.

Khamis, V. (2005). Post-traumatic stress disorder among school age Palestinian children. Child Abuse \& Neglect, 29, 81-95.

Kilpatrick, D. G., Acierno, R., Saunders, B., Resnick, H. S., Best, C. L. \& Schnurr, P. P. (2000). Risk factors for adolescent substance abuse and dependence: Data from a national sample. Journal of Consulting \& Clinical Psychology, 68, 19-30.

Kilpatrick, D. G., \& Resnick, H. S. (1993). PTSD associated with exposure to criminal victimization in clinical and community populations. In J. R. T. Davidson \& E. B. Foa (Eds.), PTSD in review: Recent research and future directions (pp. 113-143). Washington, DC: American Psychiatric Press.

Kilpatrick, D. G., Resnick, H. S., \& Freedy, J. R. (1992). Posttraumatic stress disorder field trial report: A comprehensive review of initial results. Presented at Annual Meeting of the American Psychiatric Association, Washington, DC.

Kilpatrick, D. G., Ruggiero, K. J., Acierno, R., Saunders, B. E., Resnick, H. S., \& Best, C. L. (2003). Violence and risk of PTSD, major depression, substance abuse/dependence, and comorbidity: Results from the National Survey of Adolescents. Journal of Consulting and Clinical Psychology, 71, 692-700.

Kolko, D. J., Hurlburt, M. S., Jinjin, Z., Barth, R. P., Leslie, L. K., \& Burns, B. J. (2010). Posttraumatic stress symptoms in children and adolescents referred for child welfare investigation. Child Maltreatment, 15, 48-63.

Lavi, T., \& Solomon, Z. (2005). Palestinian youth of the intifada: PTSD and future orientation. Journal of the American Academy of Child \& Adolescent Psychiatry, 44, 1176-1183.

Lee, S. J., Detels, R., Rotheram-Borus, M. J., \& Duan, N. (2007). The effect of social support on mental and behavioral outcomes among adolescents with parents with HIV/AIDS. American Journal of Public Health, 97, 1820-1826.

Lenroot, R. K., \& Giedd, J. N. (2006). Brain development in children and adolescents: Insights from anatomical magnetic resonance imaging. Neuroscience and Biobehavioral Reviews, 30, 718-729.

Levitt, J. T., Malta, L. S., Martin, A., Davis, L., \& Cloitre, M. (2007). The flexible application of a manualized treatment for PTSD symptoms and functional impairment related to the 9/11 World Trade Center attack. Behavior Research and Therapy, 45, 1419-1433.
Lipschitz, D. S., Rasmusson, A. M., Anyan, W., Cromwell, P., \& Southwick, S. M. (2000). Clinical and functional correlates of posttraumatic stress disorder in urban adolescent girls at a primary care clinic. Journal of the American Academy of Child \& Adolescent Psychiatry, 39, 1104-1111.

Lipschitz, D. S., Rasmusson, A. M., Anyan, W., Gueorguieva, R., Billingslea, E. M., Cromwell, P. F., \& Southwick, S. M. (2003). Posttraumatic stress disorder and substance use in inner-city adolescent girls. Journal of Nervous \& Mental Disease, 191, 714-721.

Lipschitz, D. S., Winegar, R. K., Hartnick, E., Foote, B., \& Southwick, S. M. (1999a). Posttraumatic stress disorder in hospitalized adolescents: Psychiatric comorbidity and clinical correlates. Journal of the American Academy of Child \& Adolescent Psychiatry, 38, 385-392.

Lipschitz, D. S., Winegar, R. K., Nicolaou, A. L., Hartnick, E., Wolfson, M., \& Southwick, S. M. (1999b). Perceived abuse and neglect as risk factors for suicidal behavior in adolescent inpatients. Journal of Nervous and Mental Disease, 187, 32-39.

Ma, X., Liu, X., Hu, X., Qiu, C., Wang, Y., Huang, Y., et al. (2011). Risk indicators for post-traumatic stress disorder in adolescents exposed to the 5.12 Wenchuan earthquake in China. Psychiatry Research, 189, 385-391.

Macdonald, A., Danielson, C. K., Resnick, H. S., Saunders, B. E., \& Kilpatrick, D. G. (2010). PTSD and comorbid disorders in a representative sample of adolescents: The risk associated with multiple exposures to potentially traumatic events. Child Abuse and Neglect, 34, 773-783.

Maschi, T. (2006). Trauma and delinquent behavior among males: The moderating role of social support. Stress, Trauma, and Crisis: An International Journal, 9, 45-72.

Maschi, T., Bradley, C., \& Morgen, K. (2008). Unraveling the link between trauma and delinquency: The mediating role of negative affect and delinquent peer exposure. Youth Violence and Juvenile Justice, 6, 136-157.

Mazza, J. J. (2000). The relationship between posttraumatic stress symptomatology and suicidal behavior in school-based adolescents. Suicide \& Life - Threatening Behavior, 30, 91-103.

Mazza, J. J., \& Reynolds, W. M. (1999). Exposure to violence in young inner-city adolescents: Relationships with suicidal ideation, depression, and PTSD symptomatology. Journal of Abnormal Child Psychology, 27, 203-213.

McNally, R. (1993). Stressors that produce posttraumatic stress disorder in children. In J. Davidson \& E. Foa (Eds.), Posttraumatic stress disorder: DSM-IV and beyond (pp. 57-74). Washington, DC: American Psychiatric Press.

Miranda, R., Scott, M., Hicks, R., Wilcox, H. C., Harris Munfakh, J. L., \& Shaffer, D. (2008). Suicide attempt characteristics, diagnoses, and future attempts: Comparing multiple attempters to single attempters and ideators. Journal of the American Academy of Child \& Adolescent Psychiatry, 47, 32-40.

Mohamai, L., Mohamadkhani, P., Dolatshahi, B., \& Golzari, M. (2010). Posttraumatic stress disorder symptoms and their comorbidity with other disorders in eleven to sixteen-year-old adolescents in the city of Bam. Iranian Journal of Psychiatry and Clinical Psychology, 16, 187-194. 
Mueser, K. T., \& Taub, J. (2008). Trauma and PTSD among adolescents with severe emotional disorders involved in multiple service systems. Psychiatric Services, 59, 627-634.

Neugebauer, R., Fisher, P. W., Turner, J. B., Yamabe, S., Sarsfield, J. A., \& Stehling-Ariza, T. (2009). Post-traumatic stress reactions among Rwandan children and adolescents in the early aftermath of genocide. International Journal of Epidemiol, 38, 1033-1045.

Ozer, E. J. (2005). The impact of violence on urban adolescents: Longitudinal effects of perceived school connection and family support. Journal of Adolescent Research, 20, 167-192.

Ozer, E. J., \& Weinsten, R. S. (2004). Urban adolescents' exposure to community violence: The role of support, school safety, and social constraints in a school-based sample of boys and girls. Journal of Clinical Child and Adolescent Psychology, 33, 463-476.

Paus, T. (2005). Mapping brain maturation and cognitive development during adolescence. Trends in Cognitive Sciences, 9, 60-68.

Pfefferbaum E. (1997). Posttraumatic stress disorder in children: A review of the past 10 years. Journal of the American Academy of Child \& Adolescent Psychiatry, 36, 1503-1511.

Prinstein, M. J., Nock, M. K., Simon, V., Aikins, J. W., Cheah, C. S. L., \& Spirito, A. (2008). Longitudinal trajectories and predictors of adolescent suicidal ideation and attempts following inpatient hospitalization. Journal of Consulting and Clinical Psychology, 76, 92-103.

Prinstein, M. J., Nock, M. K., Spirito, A., \& Grapentine, W. L. (2001). Multimethod assessment of suicidality in adolescent psychiatric inpatients: preliminary results. Journal of the American Academy of Child \& Adolescent Psychiatry, 40, 1053-1061.

Read, J. P., Ouimette, P., White, J., Colder, C., \& Farrow, S. (2011). Rates of $D S M-I V$-TR trauma exposure and posttraumatic stress disorder among newly matriculated college students. Psychological Trauma: Theory, Research, Practice, and Policy, 3, 148-156.

Reebye, P., Moretti, M. M., Wiebe, V. J., \& Lessard, J. C. (2000). Symptoms of posttraumatic stress disorder in adolescents with conduct disorder: Sex differences and onset patterns. Canadian Journal of Psychiatry, 45, 746-751.

Schaal, S., \& Elbert, T. (2006). Ten years after the genocide: Trauma confrontation and posttraumatic stress in Rwandan adolescents. Journal of Traumatic Stress, 19, 95-105.

Seedat, S., Nyamai, C., Njenga, F., Vythilingum, B., \& Stein, D. J. (2004). Trauma exposure and post-traumatic stress symptoms in urban African schools. Survey in Cape Town and Nairobi. British Journal of Psychiatry, 184, 169-175.

Seng, J. S., Graham-Bermann, S. A., Clark, M. K., McCarthy, A. M., \& Ronis, D. L. (2005). Posttraumatic stress disorder and physical comorbidity among female children and adolescents: Results from service-use data. Pediatrics, 116, 767-776.

Silva, R. R., Alpert, M., Munoz, D. M., Singh, S., Matzner, F., \& Dummit, S. (2000). Stress and vulnerability to posttraumatic stress disorder in children and adolescents. American Journal of Psychiatry, 157, 1229-1235.

Solomon, Z., \& Lavi, T. (2005). Israeli youth in the Second Intifada: PTSD and future orientation. Journal of the American Academy of Child \& Adolescent Psychiatry, 44, 1167-1175.

Steinberg, L. (2008). A social neuroscience perspective on adolescent risk-taking. Developmental Review, 28, 78-106.
Stewart, S. (1996). Alcohol abuse in individuals exposed to trauma: A critical review. Psychological Bulletin, 120, 83-112.

Stewart, S. H., Mitchell, T. L., Wright, K. D., \& Loba, P. (2004). The relations of PTSD symptoms to alcohol use and coping drinking in volunteers who responded to the Swissair Flight 111 airline disaster. Journal of Anxiety Disorders, 18, 51-68.

Storr, C. L., Ialongo, N. S., Anthony, J. C., \& Breslau, N. (2007). Childhood antecedents of exposure to traumatic events and posttraumatic stress disorder. American Journal of Psychiatry, 164, $119-125$.

Vega, W. A., Aguilar-Gaxiola, S., Andrade, L., Bijl, R. V., Borges, G., Caraveo-Anduaga, J. J., et al. (2002). Prevalence and age of onset for drug use in seven international sites: Results from the International Consortium of Psychiatric Epidemiology. Drug and Alcohol Dependence, 68, 285-297.

Wang, L., Long, D., Li, Z., \& Armour, C. (2011). Posttraumatic stress disorder symptom structure in Chinese adolescents exposed to a deadly earthquake. Journal of Abnormal Child Psychology, 39, 749-758.

Wichstrom, L. (2000). Predictors of adolescent suicide attempts: a nationally representative longitudinal study of Norwegian adolescents. Journal of the American Academy of Child \& Adolescent Psychiatry, 39, 603-610.

Zatzick, D. F., Kang, S., Muller, H., Russo, J. E., Rivara, F. P., \& Katon, W., et al. (2002). Predicting posttraumatic distress in hospitalized trauma survivors with acute injuries. American Journal of Psychiatry, 159, 941-946.

Zona, K. \& Milan, S. (2011). Gender differences in the longitudinal impact of exposure to violence on mental health in urban youth. Journal of Youth and Adolescence, 40, 1674-1690.

Chemtob, C. M., \& Taylor, T. L. (2002). Treatment of traumatized children. In R. Yehuda (Ed.), Treating trauma survivors with PTSD (pp. 75-126). Washington, DC: American Psychiatric.

Cohen, J. A., Bukstein, O. G., Walter, H. J., Benson, S. R., Chrisman, A. K., Farchione, T. R, Medicus, J. (2010). Practice parameter for the assessment and treatment of children and adolescents with posttraumatic stress disorder. Journal of the American Academy of Child and Adolescent Psychiartry, 49, 414-430.

Cohen, J. A., \& Scheeringa, M. S. (2009). Post-traumatic stress disorder diagnosis in children: Challenges and promises. Dialogues in Clinical Neuroscience, 11, 91-99.

Pearlman, M. Y., Schwalbe, K. D., \& Cloitre, M. (2010). Grief in childhood: Fundamentals of treatment in clinical practice. Washington, DC: American Psychological Association.

Silva, R. R. (2004). Posttraumatic stress disorders in children and adolescents: Handbook. New York: Norton.

\section{Bios}

Kate Nooner, Ph.D., is an Assistant Professor at Montclair State University and a Research Scientist at the Nathan S. Kline Institute. Her area of research focuses on the ways in which maltreatment related trauma impact developmental brain and behavior trajectories in childhood and adolescence. 
L. Oriana Linares, Ph.D. is an Associate Professor of Pediatrics and Psychiatry at Mount Sinai School of Medicine (MSSM) Adolescent Health Center. Her major research interests include effective psychosocial interventions for young children in foster care, developmental psychopathology among maltreated children and co-parenting processes in foster care. Dr. Linares serves in several NIH review panels and the Board of Scientific Counselors at the National Center for Injury and Violence Prevention of the CDC.

Jessica Batenjane, B.A., earned her bachelors in psychology in 2010 from Montclair State University. She is currently enrolled in a doctoral program in clinical psychology

Rachel A. Kramer, B.A., earned her bachelors in psychology in 2011 from Montclair State University. She graduated with high honors and is beginning graduate studies in psychology.
Marylene Cloitre, Ph.D., is the Associate Director of Research at the National Center for PTSD at the Palo Alto Veterans Health Care System in Palo Alto, California. She is also an adjunct Professor in the Department of Psychiatry and the Department of Child and Adolescent Psychiatry at the New York University Langone Medical Center in New York City. Her research for the past 20 years has focused on the adverse effects of early life trauma and the treatment of complex forms of PTSD.

Raul Silva, M.D., is licensed psychiatrist and has been listed in New York's Best Doctors in the field of Child and Adolescent Psychiatry since 2003. He has held faculty appointments as an Associate Professor at Columbia University's College of Physicians \& Surgeons and at the New York University (NYU) School of Medicine. Dr. Silva has authored and coauthored over 200 published articles, editorials, abstracts, chapters and books. He has been Principal Investigator and Co-Investigator for 21 research projects in his field. 